\title{
Cross-Cultural Employee Motivation in International Companies
}

\author{
Binglu Zhao, Ying Pan \\ School of Business Administration, South China University of Technology, Guangzhou, China \\ Email: scutbm@163.com
}

How to cite this paper: Zhao, B.L. and Pan, Y. (2017) Cross-Cultural Employee Motivation in International Companies. Journal of Human Resource and Sustainability Studies, 5, 215-222. https://doi.org/10.4236/jhrss.2017.54019

Received: July 11, 2017

Accepted: August 29, 2017

Published: November 23, 2017

Copyright (๐) 2017 by authors and Scientific Research Publishing Inc. This work is licensed under the Creative Commons Attribution International License (CC BY 4.0).

http://creativecommons.org/licenses/by/4.0/

(c) (i) Open Access

\begin{abstract}
Nowadays, more and more employees come from different countries and regions in international companies and how to effectively motivate these employees becomes a very important issue. This study combines a lot of existing research results with the actual business operation situations. For cross-cultural employees, elaborating on influencing factors and mechanism design of the motivation in detail from significance of work, hierarchy of needs, and dichotomy of internal and external factors as well as the reward and punishment mechanism. It finds that the most fitting motivation methods are different for employees under different cultural backgrounds and provides some references and suggestions for cross-cultural human resource management in international companies.
\end{abstract}

\section{Keywords}

Employee Motivation, Cross-Cultural Research, International Companies, Human Resource Management

\section{Introduction}

Under the current international background, more and more enterprises begin to hire employees from different countries, which is more common in international enterprises. Employees from different cultural backgrounds have different understandings and perceptions about management and leadership, and they also have different perspectives and behaviors. In order to improve the effectiveness of management, enterprises must face the challenges of cultural differences in human resource management, and must seriously consider and solve the problems caused by cross-cultural factors.

Employee incentive is an important part of human resource management in enterprises, which means the incentive to motivate employees. In other words, it 
is to mobilize the enthusiasm and initiative of employees in a variety of ways, so as to finish the task and realize the goal of enterprises with full of quantity and quality. Effective incentive mechanism can ignite the enthusiasm of employees and stimulate their inner potential, so that they can make unremitting efforts and dedicate themselves to the realization of enterprises' goals [1].

Therefore, how should international enterprises' managers deal with incentives for cross-cultural employees?

Hofstede believes that the measurement of a nation's or organizational culture can be divided into five dimensions: individualism and collectivism, power distance, uncertainty avoidance, masculinity and femininity, long-term orientation and short-term orientation. Applying this cultural difference theory to employees from different cultural backgrounds, we can draw some conjectures about the incentive:

1) High individualism means that employees are more likely to be motivated by opportunities for personal promotion and autonomy; however, collectivism (or low individualism) means that employees are more likely to be motivated by finishing collective goals and receiving collective support.

2) High power distance implies that incentive factors exist in the relationship between employees and managers, while low power distance means employees are more likely to be motivated by team work and peer relationships.

3) High uncertainty avoidance signifies employee's need for job security; on the other hand, those employees with low uncertainty avoidance tend to be encouraged by opportunities for changes and quick promotions.

4) High masculinity means that most employees can accept traditional social work and role tasks, but in a more feminine culture, the boundaries are relatively obscure and employees are stimulated by more flexible role divisions and work networks.

5) High long-term orientation indicates that employees may be motivated by the personal career path described by the enterprise, while short-term orientation means that employees are more concerned about the immediate salary and other treatment conditions.

The wrong judgments of these cultural variables in the workplace will not only lead to the failure of the incentive mechanism, but also may lead to unpredictable negative impacts. In Thailand, for example, the individual value incentive plan deviates from the tradition of collective cooperation in society. Therefore, the introduction of the individual value incentive plan will reduce productivity instead of improving it in Thailand employees, because they are psychologically habitual to refuse to compete openly.

As a result, we must understand their needs, goals, values and expectations when considering how to motivate employees from different cultures. No matter what their nationality or cultural background is, they always hope that their needs can be satisfied [2]. But what are their needs? What do they want to achieve? What kind of incentive can motivate them to achieve the goals? Next, 
we will analyze the cross-cultural employee incentive from four aspects: significance of work, hierarchy of needs, and dichotomy of internal and external factors as well as the reward and punishment mechanism.

\section{The Significance of Working for Cross-Cultural Employees}

For employees, work has six important value significances: 1) to provide the income needed for living; 2) to be fun and bring satisfaction; 3) to provide links with others; 4) to provide ways of serving the community; 5) to make individuals not idle; 6) to bring the social status and prestige.

Taking the overall cultural background into account, the comparison of working significance has a broader meaning. For instance, Thai people like to play more during the workday. And they like to play a little more during their workday. On the contrary, most Chinese employees, German employees and American employees have a more serious attitude towards work. Especially in China, the enterprise management is mostly work oriented, in which Chinese employees are facing the five-day workday plus night or weekend overtime. Even if they are overtired, they must finish their work on time. This is the real life which Chinese employees are used to. Japanese employees attach little importance to the social status and prestige that work brings. It is because this kind of need can be met in other areas of their lives, such as through the family or community. For employees from the Middle East, religion plays a major role in all aspects of life (including work). The working philosophy of Islam holds that work is the duty to achieve perfection and work motivation has the highest position. Muslims believe that work is a kind of virtue, as well as a need for balance between personal and social life. Employees in Arabia define life values through the contribution of individuals to their families, and work is considered as a decisive factor in the individual's ability to enjoy social life and family life.

There are other factors that can also affect working significance in employees' perceptions, such as the relative affluence level of their countries [3]. When people's living condition is high, the significance of work is more than just providing basic living economy. Economic disparities among different countries lead to different attitudes towards work in different countries. In particular, young people in the Far East and Middle East countries have the highest sense of work ethic and a sense of achievement (A sense of achievement means to master a certain kind of knowledge, skill, and so on through a sustained effort).

Such researches suggest that there are many reasons for employees' different attitudes towards work, including cultural, economic, and other reasons [4]. When we look at the needs and motivations of cross-cultural employees in the workplace, we must take these complex reasons into account, so that the designed incentive mechanism can play the expected role.

\section{The Hierarchy of Needs for Cross-Cultural Employees}

For a manager of an international enterprise, how can he effectively motivate 
cross-cultural employees? Of course, he can find the answer by drawing on the management experience of people who have worked in that country, or by examining the culture of the region to infer a possible incentive structure type [5]. In addition, researches and comparisons of employees' national cultural backgrounds can also help him find some answers.

Some scholars use Maslow's hierarchy of needs to study the incentives of employees from different countries. They find that employees with different nationalities have the common needs and target group. This group includes: 1) objectives, such as working area, working time, working environment, marginal welfare and working security; 2) the relationship with colleagues and superiors; 3 ) the working challenges and opportunities to use their skills. Finally, the conclusion is that the demand group is consistent among people with different nationalities, and these demand groups confirm Maslow's hierarchy of needs.

How employees meet their needs to the greatest extent, which varies among different cultures. Employees from different countries have different perceptions for what occupies the main place in the sources of job satisfaction. For instance, Chinese employees, Israeli employees, and Korean employees believe that "achievement" is the most important because it meets the needs of self-actualization; however, for German employees, Holland employees and American employees, "the fun of work" is the most important.

A clear conclusion can be drawn that employees of different cultures have similar needs, but the degree of satisfaction they get from work is different. It is found in many international enterprises that the needs of local employees and their ways for work are different from those of domestic employees. Japan's Mazda Motor Corp has also met this problem in its plant in Michigan. Japanese enterprises tend to show their recognition of their employees through medals, attention and applause, and some Japanese employees may even be angry when they receive material rewards, because this kind of rewards mean that they have to work harder to get material rewards again, not by other means. Japanese companies focus on the teams or the enterprises' overall goals, while the Americans pay attention to individual goals, achievements and material rewards.

Compared with Western culture, in Oriental cultures, the overall needs of the society, rather than the individual needs are paid more attention to. The needs of Chinese employees include four levels: 1) individual wealth; 2) physiological needs; 3 ) the sense of security; and 4) self-realization in society (see Figure 1).

It is difficult to evaluate and measure the individual needs of Chinese employees as China is a highly collectivist country [6]. It can be seen from the cultural development of China, the political belief plays a dominant role in the stimulation of many respects [7]. As the backbone of the industrial system, the enterprise managers and workers are given clear and detailed instructions which are what they are expected to follow as members of the factories, the workshops, or the work groups [8]. In China, it is very important for ordinary employees to become members of the work group. At the same time, money is another incentive. According to the history, Chinese employees have more pursuit of savings. 


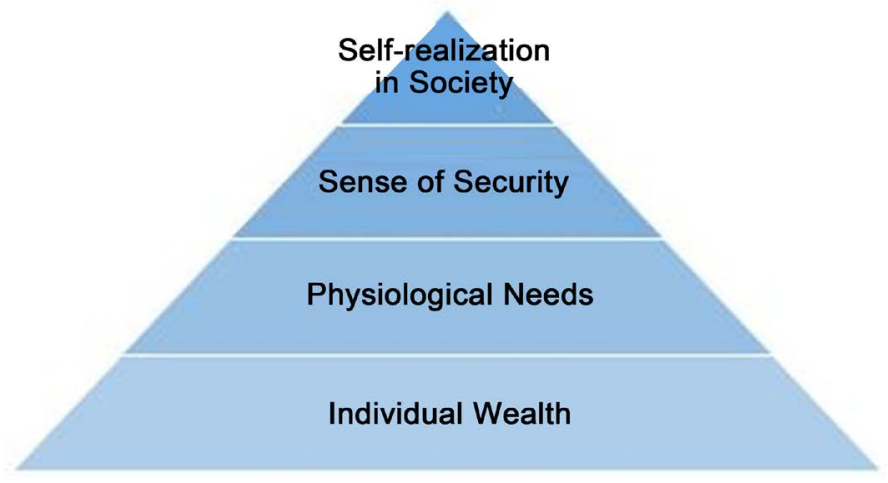

Figure 1. A pyramid for the needs of Chinese employees.

\section{Dichotomy of Internal and External Factors for Cross-Cultural Employees}

The dichotomy of internal and external factors theory of Herzberg includes two aspects: hygiene factors (external factors) and motivation factors (internal factors). Hygiene factors are what causes dissatisfaction among employees in a workplace. When hygiene factors cannot be satisfied, it is easy for employees to produce discontent, negative sabotage, and even lead to strikes and other confrontational behavior. But when hygiene factors have been improved to some extent, no matter how the improvement efforts are often difficult to make employees feel satisfied. So it is difficult to further stimulate the work of the enthusiasm of the staff, so the hygiene factor: the opposite of dissatisfaction is no dissatisfaction. Such as salary remuneration, working conditions, corporate policy, administration, labor protection, leadership level, welfare, security measures, interpersonal relationships are hygiene factors. These factors are part of the working environment and working relationship factors, and the necessary conditions to maintain the psychological integrity of workers. That is why they are called maintenance factors. They cannot directly stimulate for workers, but they are preventive. Motivation factors are factors that make employees feel satisfied. Motivation factors to make employees feel satisfied with the results, can greatly stimulate the enthusiasm of the work of staff to improve labor productivity. But even if the managers do not give their satisfaction to meet, often do not make employees feel dissatisfied. So for the motivation factors, the opposite of satisfaction is not dissatisfaction. On the use of the Herzberg model, the conclusions of the study which focus on employees from different countries help us to test whether the Herzberg model is universally applicable in different cultural contexts.

In the context of the international culture, the study of incentives is necessary. But the current large number of research results cannot determine which is more effective incentives for employees between the internal factor and external factor, more accurately speaking, effective incentives are based on specific circumstances [9]. In many multinational companies, savvy managers will often ask the locals, and use all the information they have about the relevant cultural 
and subcultural to determine the most appropriate incentives in the environment at that time [10]. In addition, experienced managers will consciously avoid the attitude with some sense of racial superiority, otherwise they will imagine the purpose of cross-cultural staff motivation or work habits by their own point of view. They will not make a negative judgment because of the level of motivation and the individual differences of the employees.

\section{Reward and Punishment Mechanism for Cross-Cultural Employees}

For employees, the reward and punishment mechanism is also a very important incentive. The former is often called the positive incentive and the latter is called negative incentive.

Rewards usually include money, social status, job duties, career, etc. In different cultural backgrounds, the focus of the reward varies a lot. In the United States, the specific patterns of incentives are different due to the enterprises' structures and the industry characteristics [11]. In general, the employees' professional ability in practical work is the main basis for the rewards. In Japan, the incentive mechanism is mainly based on the employees' qualifications and record of service. Besides, there is also a gap between the incentive for the stable labor force and for the temporary labor force made up of women who are leaving office for the family. In general, the stable labor force in Japan gains more rewards in terms of pay, benefits and task allocation than the temporary labor force [12]. Japanese employees emphasize the reward for the group's achievements more, rather than the individual reward. However, recognition and affection are of great importance for Chinese employees [13]. The employees and departments always complete with each other in order to get praised by the managers at the annual summary conference or celebration, which can also be applied to Korean employees.

As for the punishment on the employees, the reasons and significance of the punishment should first of all be recognized by the employees of different cultural backgrounds [14]. In the development of specific punishments, the taboos and the bottom lines of different races of employees should also be taken into account [15]. Before the implementation of the provisions, it should take advice from all the employees to ensure the punishments' the rationality and feasibility so that good effects of incentive can be achieved.

\section{Conclusion}

Based on the research results of scholars at home and abroad, the thesis discusses the incentives for cross-cultural employees in international enterprises from four aspects which are significance of work, hierarchy of needs, and dichotomy of internal and external factors as well as the reward and punishment mechanism. It is found that the characteristics and mechanisms of effective incentives for employees of different cultures are different. In practical application, 
the managers of international enterprises should be good at observing and discovering the characteristics and inner needs of cross-cultural employees and design corresponding incentive mechanism, making it easy to achieve good results as well as fully arouse the employees' enthusiasm for work so that the organizational performance can be improved. In the future, we can combine case study, questionnaire or secondary data to carry out further research on cross-cultural employee motivation.

\section{References}

[1] Ahmad, K. (2013) Leadership and Work Motivation from the Cross Cultural Perspective. International Journal of Commerce \& Management, 19, 72-84. https://doi.org/10.1108/10569210910939681

[2] Ang, S.H. (2000) The Power of Money: A Cross-Cultural Analysis of Business-Related Beliefs. Journal of World Business, 35, 43-60. https://doi.org/10.1016/S1090-9516(99)00033-4

[3] Park, J. and Nawakitphaitoon, K. (2017) The Cross-Cultural Study of LMX and Individual Employee Voice: The Moderating Role of Conflict Avoidance. Human Resource Management Journal, 4, 1-17.

[4] Chen, G., Kirkman, B.L., Kim, K., Farh, C.I.C. and Tangirala, S. (2010) When Does Cross-Cultural Motivation Enhance Expatriate Effectiveness? A Multilevel Investigation of the Moderating Roles of Subsidiary Support and Cultural Distance. Academy of Management Journal, 53, 1110-1130. https://doi.org/10.5465/AMJ.2010.54533217

[5] Ishii, K., Mojaverian, T., Masuno, K. and Kim, H.S. (2017) Cultural Differences in Motivation for Seeking Social Support and the Emotional Consequences of Receiving Support: The Role of Influence and Adjustment Goals. Journal of Cross-Cultural Psychology, 48, 1442-1456. https://doi.org/10.1177/0022022117731091

[6] Tung, R.L. (1981) Patterns of Motivation in Chinese Industrial Enterprises. Academy of Management Review, 6, 481-489.

[7] Nardon, L. and Steers, R.M. (2014) Managing Cross-Cultural Encounters: Putting Things in Context. Organizational Dynamics, 43, 138-145.

https://doi.org/10.1016/j.orgdyn.2014.03.008

[8] Jamal, M. (2015) Job Stress and Employee Well-Being: A Cross-Cultural Empirical Study. Stress \& Health, 15, 153-158.

[9] Jönsson, S., Denti, L., Chen, K. and Muhonen, T. (2013) Social Climate as a Mediator between Leadership Behavior and Employee Well-Being in a Cross-Cultural Perspective. Journal of Management Development, 32, 1040-1055. https://doi.org/10.1108/JMD-02-2012-0034

[10] Liu, S., Schuler, R.S. and Zhang, P. (2013) External Learning Activities and Employee Creativity in Chinese R\&D Teams. Cross Cultural Management-An International Journal, 20, 429-448. https://doi.org/10.1108/CCM-10-2012-0088

[11] Jiao, C., Richards, D.A. and Hackett, R.D. (2013) Organizational Citizenship Behavior and Role Breadth: A Meta-Analytic and Cross-Cultural Analysis. Human Resource Management, 52, 697-714. https://doi.org/10.1002/hrm.21555

[12] Ahammad, M.F., Tarba, S.Y., Liu, Y. and Glaister, K.W. (2014) Knowledge Transfer and Cross-Border Acquisition Performance: The Impact of Cultural Distance and Employee Retention. International Business Review, 25, 66-75. 
https://doi.org/10.1016/j.ibusrev.2014.06.015

[13] Farndale, E. and Murrer, I. (2015) Job Resources and Employee Engagement: A Cross-national Study. Journal of Managerial Psychology, 30, 610-626. https://doi.org/10.1108/JMP-09-2013-0318

[14] Berberoglu, F., Dalyan, C.C., Wong, A., et al. (2013) Organizational Practices across Cultures: An Exploration in Six Cultural Contexts. International Journal of Cross Cultural Management, 14, 105-125.

[15] Garczynski, A.M., Waldrop, J.S., Rupprecht, E.A. and Grawitch, M.J. (2013) Differentiation between Work and Nonwork Self-Aspects as a Predictor of Presenteeism and Engagement: Cross-Cultural Differences. Journal of Occupational Health Psychology, 18, 417-429. https://doi.org/10.1037/a0033988 